\title{
MicroRNA-383-5p inhibits the proliferation and promotes the apoptosis of gastric cancer cells by targeting cancerous inhibitor of PP2A
}

\author{
XINXIN LI, JINPENG YUAN, QIANGJIAN CAO, AOSI XIE and JUNTIAN CHEN \\ Department of Gastrointestinal Surgery, The First Affiliated Hospital of Shantou University Medical College, \\ Shantou, Guangdong 515041, P.R. China
}

Received December 4, 2019; Accepted March 20, 2020

DOI: $10.3892 / \mathrm{ijmm} .2020 .4603$

\begin{abstract}
The aberrant expression of microRNA (miRNAor miR)-383-5p has been found in numerous types of cancer. However, the function of miR-383-5p in gastric cancer (GC) remains elusive and requires further investigation. In the present study, the level of miR-383-5p and cancerous inhibitor of PP2A (CIP2A) in GC cell lines was determined by reverse transcription-quantitative PCR analysis. GC cell proliferation, apoptosis and cell cycle distribution were determined by the MTT assay and flow cytometry, respectively. The mRNA target of miR-383-5p was identified by dual luciferase activity assay. It was observed that the expression of miR-383-5p was lower and that of CIP2A was higher in GC cells compared with the GES-1 normal human gastric epithelial cell line. Transfectoin with miR-383-5p mimic significantly inhibited GC cell proliferation, while it promoted cell apoptosis and $\mathrm{G}_{0} / \mathrm{G}_{1}$ arrest by targeting CIP2A. Taken together, the findings of the present study demonstrate that miR-383-5p inhibits $\mathrm{GC}$ cell proliferation and promotes apoptosis and $\mathrm{G}_{0} / \mathrm{G}_{1}$ arrest by targeting CIP2A, indicating that targeting miR-383-5p may hold promise as a future therapeutic strategy for patients with GC.
\end{abstract}

\section{Introduction}

GC is the fourth most frequent type of cancer worldwide, and it is characterized by a high mortality rate (1). GC is one of the most serious public health concerns globally, particularly in China (2). Despite the recent advances in the treatment of $\mathrm{GC}$, the prognosis of patients with advanced $\mathrm{GC}$ remains poor.

Correspondence to: Dr Juntian Chen, Department of Gastrointestinal Surgery, The First Affiliated Hospital of Shantou University Medical College, 57 Changping Road, Shantou, Guangdong 515041, P.R. China E-mail: chenjuntianstmc@163.com

Key words: microRNA-383-5p, gastric cancer, cancerous inhibitor of PP2A
Consequently, the investigation and development of novel therapeutic strategies for GC is of utmost importance.

MicroRNAs (miRNAs or miRs) are a type of small non-coding RNAs, which function by negatively regulating the expression of mRNAs by base pairing with their 3'-untranslated region (UTR) $(3,4)$. miRNAs play a key role in the proliferation, apoptosis, metastasis and metabolism of cancer cells (5). The aberrant expression of miRNAs has been observed in various types of cancer, such as breast cancer (6), osteosarcoma (7) and GC (8). In 2018, miR-383-5p was found to act as a tumor suppressor in hepatocellular carcinoma (9). Since then, several studies on the function of miR-383-5p have been published in several cancer types. For example, miR-383-5p has been shown to suppress the proliferation and metastasis of breast cancer cells (10). LINC01128 has also been shown to promote the development of cervical cancer by sponging miR-383-5p (11). RP11-284F21.9 induces the development of oral squamous cell carcinoma by sponging miR-383-5p (12). Moreover, the decreased expression of miR-383-5p has been shown to lead to the proliferation and migration of GC cells (13), and miR-383-5p has been reported to suppress the development of GC by targeting HDAC9 (14).

Cancerous inhibitor of PP2A (CIP2A) was first confirmed to be a tumor-associated auto-antigen in GC and liver cancer (15), the overexpression of which was identified in various types of cancer, such as lung (16), cervical (17) and prostate (18) cancers, as well as GC (19). miR-383-5p has been proven to regulate the development of lung cancer by targeting CIP2A (20). However, to date, at least to the best of our knowledge, there is no study available on the association between miR-383-5p and CIP2A in GC. Thus, the aim of the present study was to investigate whether miR-383-5p regulates the development of GC by targeting CIP2A.

\section{Materials and methods}

Cell culture. The 293T cell line, the normal human gastric epithelial cell line GES-1, and two GC cell lines (AGS and HGC-27) were purchased from the American Type Culture Collection. The cells were cultured in Dulbecco's modified Eagle's medium (Invitrogen; Thermo Fisher Scientific, Inc.), supplemented with 5\% fetal bovine serum (Invitrogen; Thermo 
Fisher Scientific, Inc.), in a humidified incubator with $95 \%$ air and $5 \% \mathrm{CO}_{2}$.

pcDNA treatment. The full length of CIP2A was amplified from the cDNA of GES-1 cells and cloned into the pcDNA3.1 plasmid to construct pcDNA3.1-CIP2A. The cells were then transfected with pcDNA3.1 or pcDNA3.1-CIP2A (2 $\mu \mathrm{g})$ using Lipofectamine 2000 (Invitrogen; Thermo Fisher Scientific, Inc.) according to the manufacturer's instructions. At $48 \mathrm{~h}$ following transfection, the cells were collected for use in the subsequent experiments.

Transfection with miR mimic. miR-NC mimic and miR-383-5p mimic were synthesized by Ambion (Thermo Fisher Scientific, Inc.). miR-NC mimic (100 $\mathrm{nM})$ or miR-383-5p mimic (100 nM) were transfected into cells using Lipofectamine 2000 (Invitrogen; Thermo Fisher Scientific, Inc.) according to the manufacturer's instructions, followed by incubation at $37^{\circ} \mathrm{C}$. At $48 \mathrm{~h}$ following transfection, the cells were collected for use in the subsequent experiments.

miR target prediction. TargetScan 7.1 database (http://www. targetscan.org/vert_71/) was used to identify the potential target mRNAs of miR-383-5p.

Luciferase reporter gene assay. The wild-type (WT) or mutant-type (MT) 3'-UTR of CIP2A were constructed by RiboBio and inserted into the pmiR-REPORT vector (Ambion; Thermo Fisher Scientific, Inc.), which was then transfected into cells using Lipofectamine 2000 (Invitrogen; Thermo Fisher Scientific, Inc.) according to the manufacturer's instructions, and incubated at $37^{\circ} \mathrm{C}$. At $48 \mathrm{~h}$ following transfection, the luciferase activity was determined by the Dual Luciferase Reporters Assay System (Promega Corporation) on a LuminoskanTM Ascent Microplate Luminometer (Thermo Fisher Scientific, Inc.). The luciferase activity was normalized to Renilla luciferase activity.

Reverse transcription-quantitative PCR ( $R T$-qPCR) analysis. Total RNA was extracted using TRIzol reagent (Invitrogen; Thermo Fisher Scientific, Inc.) according to the manufacturer's instructions. Reverse transcription was conducted at $42^{\circ} \mathrm{C}$ for $15 \mathrm{~min}$ followed by incubation at $85^{\circ} \mathrm{C}$ for $5 \mathrm{sec}$ using the TaqMan Reverse Transcription kit (Applied Biosystems; Thermo Fisher Scientific, Inc.) according to the manufacturer's instructions. RT-qPCR was conducted using the Applied Biosystems 7300 Real-Time PCR system (Applied Biosystems; Thermo Fisher Scientific, Inc.) with the TaqMan Universal PCR Master Mix (Thermo Fisher Scientific, Inc.). The primers used were as follows: CIP2A forward, 5'-AAT TTAGTAAAGACCCTGATCTG-3' and reverse, 5'-CAGATC AGGGTCTTTACTAAATT-3'; GAPDH forward, 5'-GGA GCGAGATCCCTCCAAAAT-3' and reverse, 5'-GGCTGT TGTCATACTCTCATGG-3'; miR-383-5p forward, 5'-TCG GTGTTAGTGGAAGACTAGAC-3' and reverse, 5'-GTCTAG TCTTCCACTAACACCGA -3'; U6 forward, 5'-GTGCTC GCTTCGGCAGCACAT-3' and reverse, 5'-AATATGGAA CGCTTCACGAAT-3'. The thermocycling conditions were as follows: Initial denaturation at $95^{\circ} \mathrm{C}$ for $2 \mathrm{~min}$, and 40 cycles of $95^{\circ} \mathrm{C}$ for $15 \mathrm{sec}$ and $64^{\circ} \mathrm{C}$ for $30 \mathrm{sec}$. GAPDH was used as an endogenous control for CIP2A. U6 was used as an endogenous control for miR-383-5p. The relative expression levels were calculated using the $2^{-\Delta \Delta \mathrm{cq}}$ method (21).

Western blot analysis. Total protein lysates were prepared by radioimmunoprecipitation assay (RIPA) lysis buffer (Sigma-Aldrich; Merck KGaA) at $4^{\circ} \mathrm{C}$. The protein concentration was determined using a bicinchoninic acid kit (Pierce; Thermo Fisher Scientific, Inc.). Protein samples $(20 \mu \mathrm{g})$ were separated by $10 \%$ SDS-PAGE and transferred onto PVDF membranes. The PVDF membranes were then blocked by 5\% BSA (Sigma-Aldrich; Merck KGaA) at room temperature for $1 \mathrm{~h}$, probed with primary antibodies to CIP2A (dilution 1:1,000; \#14805), p21 (dilution 1:1,000; \#2947), CDK4 (dilution 1:1,000; \#12790), Cyclin D1 (dilution 1:1,000; \#55506), Bcl-2 (dilution 1:1,000; \#4223), BAX (dilution 1:1,000; \#5023), $\beta$-actin (dilution 1:1,000; \#4970) which were purchased form Cell Signaling Technology at $4^{\circ} \mathrm{C}$ overnight and horseradish peroxidase-conjugated secondary antibody (dilution 1:1,000; \#7074, Cell Signaling Technology) at room temperature for $2 \mathrm{~h}$. Finally, the bands were visualized by the enhanced chemiluminescence detection reagent using the ChemiDoc XRS system (Bio-Rad Laboratories, Inc.).

Cell proliferation assay. Cell proliferation was assessed by MTT assay (Sigma-Aldrich; Merck KGaA) as advised in the manufacturer's manual. Cells $\left(3 \times 10^{3} / 100 \mu \mathrm{l}\right)$ were plated into each well of the 96 -well plates and cultured at $37^{\circ} \mathrm{C}$ for 3 days. Subsequently, the dye solution $(15 \mu \mathrm{l})$ was added to each well and incubated at $37^{\circ} \mathrm{C}$ for a further $4 \mathrm{~h}$. Stop solution $(100 \mu \mathrm{l})$ was then added to each well. The colorimetric absorbance was recorded with the SpectraMax Plus (Molecular Devices LLC) at $570 \mathrm{~nm}$.

Cell cycle analysis. Cells $\left(1 \times 10^{6}\right)$ were collected and fixed by $70 \%$ ice-cold ethanol at $4^{\circ} \mathrm{C}$ overnight. The cells were then re-suspended in PBS $(1 \mathrm{ml})$ supplemented with bovine pancreatic RNase A (100 $\mu \mathrm{g} / \mathrm{ml}$, Sigma-Aldrich; Merck $\mathrm{KGaA}$ ) and $40 \mu \mathrm{g} / \mathrm{ml}$ propidium iodide (PI; Sigma-Aldrich; Merck $\mathrm{KGaA}$ ) for $30 \mathrm{~min}$ at $4^{\circ} \mathrm{C}$. Subsequently, cell cycle analysis was carried out on a Becton-Dickinson FACSCalibur cytometer (BD Biosciences) and analyzed by ModFit software version 3.2.1 (Verity Software House).

Cell apoptotic analysis. Cell apoptosis was determined using the Annexin V-fluorescein isothiocyanate (FITC) apoptosis kit (Merck $\mathrm{KGaA}$ ) according to the manufacturer's instructions. Cells were incubated in ice-cold $1 \mathrm{X}$ binding buffer $(500 \mu \mathrm{l})$ containing Annexin V-FITC $(2.3 \mu \mathrm{l})$ for $10 \mathrm{~min}$ at $4^{\circ} \mathrm{C}$, followed by incubation at room temperature for $10 \mathrm{~min}$ in the dark. Subsequently, the cells were re-suspended in ice-cold $1 \mathrm{X}$ binding buffer $(500 \mu \mathrm{l})$ supplemented with PI $(5 \mu \mathrm{l})$, and incubated at room temperature for $15 \mathrm{~min}$. The signals of Annexin V-FITC and PI were detected using a flow cytometer (FACSCalibur $^{\mathrm{TM}}$; BD Biosciences).

Statistical analysis. All experiments were performed at least 3 times. The values are expressed as the means \pm standard error of the mean. Differences between 2 groups were analyzed using an unpaired Student's t-test, while differences 
among 3 groups were analyzed by one-way analysis of variance followed by Newman-Keuls test. Values of $\mathrm{P}<0.05$ were considered to indicate statistically significant differences.

\section{Results}

miR-383-5p expression is decreased in GC cell lines. The expression level of miR-383-5p was assessed in GC cell lines. RT-qPCR analysis revealed that the miR-383-5p expression level was significantly lower in the GC cell lines (AGS and HGC-27) compared with the GES-1 normal gastric epithelial cell line (Fig. 1), which were then used in the subsequent experiments.

miR-383-5p directly targets CIP2A. Using the online open access database, TargetScan 7.1 (http://www. targetscan. org/vert_71/), CIP2A was selected as a candidate target mRNA for miR-383-5p. The potential CIP2A 3'-UTR fragments (WT and MT) are presented in Fig. 2A. In the 293T cell line, miR-383-5p mimic induced a significantly lower luciferase activity in the WT CIP2A 3'-UTR luciferase reporter plasmid, whereas no significant alteration was detected in the luciferase activity of the MT plasmid (Fig. 2B).

$C I P 2 A$ expression is increased in $G C$ cell lines. The expression of CIP2A in the GC cell lines, AGS and HGC-27, was then investigated by RT-qPCR analysis and western blot analysis. It was observed that the expression of CIP2A at the mRNA (Fig. 3A) and protein (Fig. 3B and C) level was significantly higher in the AGS and HGC-27 GC cells compared with that in the normal gastric epithelial cell line, GES-1.

Transfection of miR-383-5p mimic and pcDNA3.1-CIP2A. RT-qPCR and western blot analysis were used to verify the transfection of miR-383-5p mimic and pcDNA3.1-CIP2A in the GC cell lines, AGS and HGC-27. For miR-383-5p, the cells were divided into 3 groups, including the control, miR-NC mimic and miR-383-5p mimic groups. The results demonstrated that the miR-383-5p level was significantly increased by transfection with miR-383-5p mimic, indicating the successful transfection of miR-383-5p mimic in the AGS and HGC-27 GC cells (Fig. 4A); furthermore, the CIP2A protein level was significantly decreased by transfection with miR-383-5p mimic in the AGS and HGC-27 GC cells (Fig. 4B and C).

For pcDNA3.1-CIP2A, the cells were divided into 3 groups, including the control,pcDNA3.1 and pcDNA3.1-CIP2A groups. The CIP2A protein level was significantly increased by transfection with pcDNA3.1-CIP2A in the AGS and HGC-27 GC cells (Fig. 4D and E), indicating the successful transfection of pcDNA3.1-CIP2A in AGS and HGC-27 GC cells.

miR-383-5p inhibits the proliferation of GC cells by targeting CIP2A. When investigating the role of miR-383-5p in human GC cell proliferation by MTT assay, compared to transfection with miR-NC mimic, transfection with miR-383-5p mimic was shown to significantly decrease AGS and HGC-27 cell proliferation, which was reversed by transfection with pcDNA3.1-CIP2A (Fig. 5A and B). p21 was negatively correlated with cell proliferation, for example,

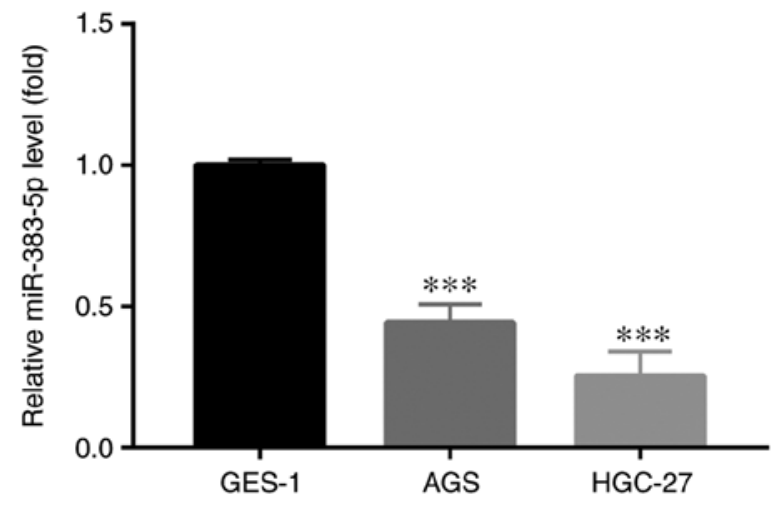

Figure 1. Expression of miR-383-5p in GC cell lines. The miR-383-5p expression level was assessed by reverse transcription-quantitative PCR analysis. ${ }^{* * * *} \mathrm{P}<0.001$ vs. GES-1. GC, gastric cancer.

\section{A}

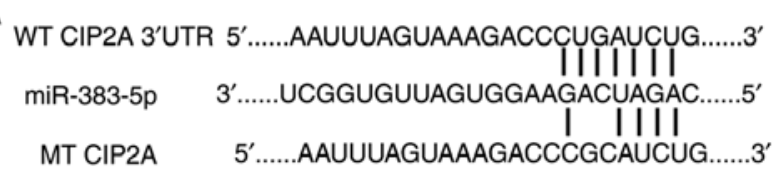

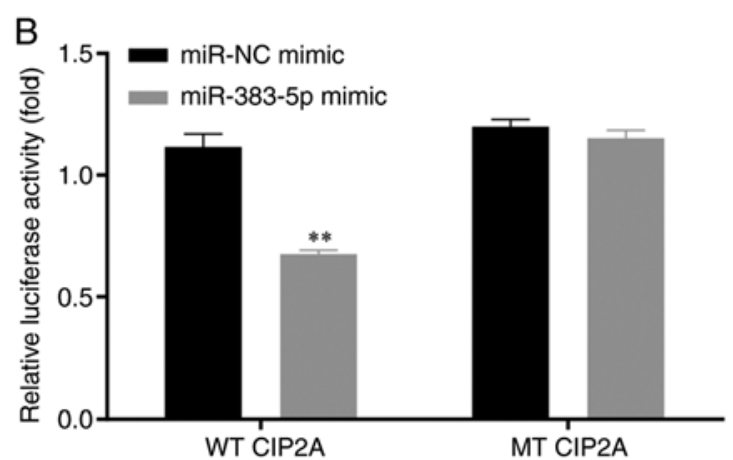

Figure 2. Interaction between miR-383-5p and CIP2A. (A) The potential WT and MT CIP2A 3'UTR fragment and miR-383-5p were investigated. (B) Effects of miR-383-5p mimic on luciferase activity. ${ }^{* *} \mathrm{P}<0.01 \mathrm{miR}-383-5 \mathrm{p}$ mimic vs. miR-NC mimic. WT, wild-type; MT, mutant type; CIP2A, cancerous inhibitor of PP2A; UTR, untranslated region.

LincRNAFEZF1-AS1 to induced proliferation of GC cells by repressing p21 (22). Western blot analysis was used to assess the protein level of $\mathrm{p} 21$. Compared to transfection with miR-NC mimic, miR-383-5p mimic significantly increased the protein level of $\mathrm{p} 21$, which was reversed by pcDNA3.1- CIP2A (Fig. 5C and D).

miR-383-5p induces the apoptosis of GC cells by targeting $C I P 2 A$. In order to elucidate the potential anti-proliferative mechanisms of action of miR-383-5p in the GC cell lines AGS and HGC-27, cell cycle progression and apoptosis were analyzed by flow cytometry.

Compared to transfection with miR-NC mimic, miR-383-5p mimic significantly increased the proportion of cells in the $G_{1}$ phase and decreased the proportion of cells in the $S$ phase, which was reversed by transfection with pcDNA3.1-CIP2A (Fig. 6A-D). Cyclin D1 and CDK4 are associated with the progression of the cell cycle; for example, RN181 regulates the activity of cyclin D1-CDK4, thus controlling the progression from the $G_{1}$ to the $S$ phase 
A

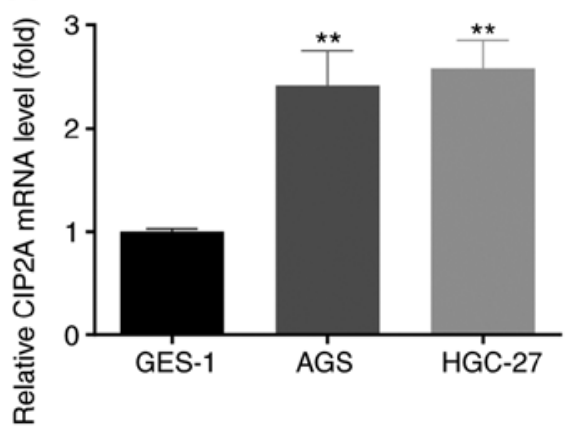

C

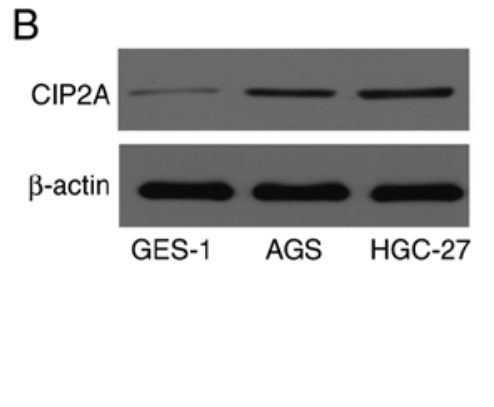

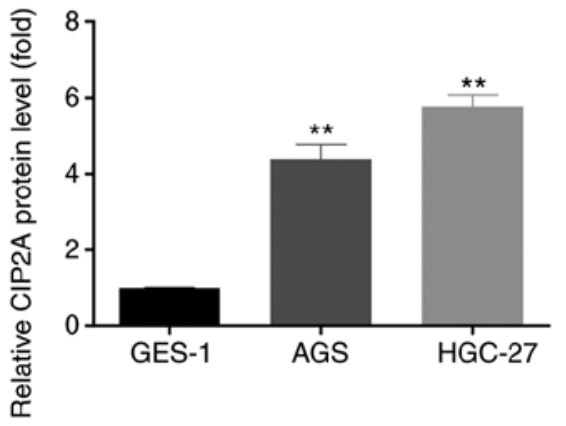

Figure 3. Expression of CIP2A in GC cell lines. (A-C) The CIP2A mRNA and protein expression levels were assessed by reverse transcription-quantitative PCR analysis and western blotting, respectively. ${ }^{* *} \mathrm{P}<0.01$ vs. GES-1. CIP2A, cancerous inhibitor of PP2A; GC, gastric cancer.

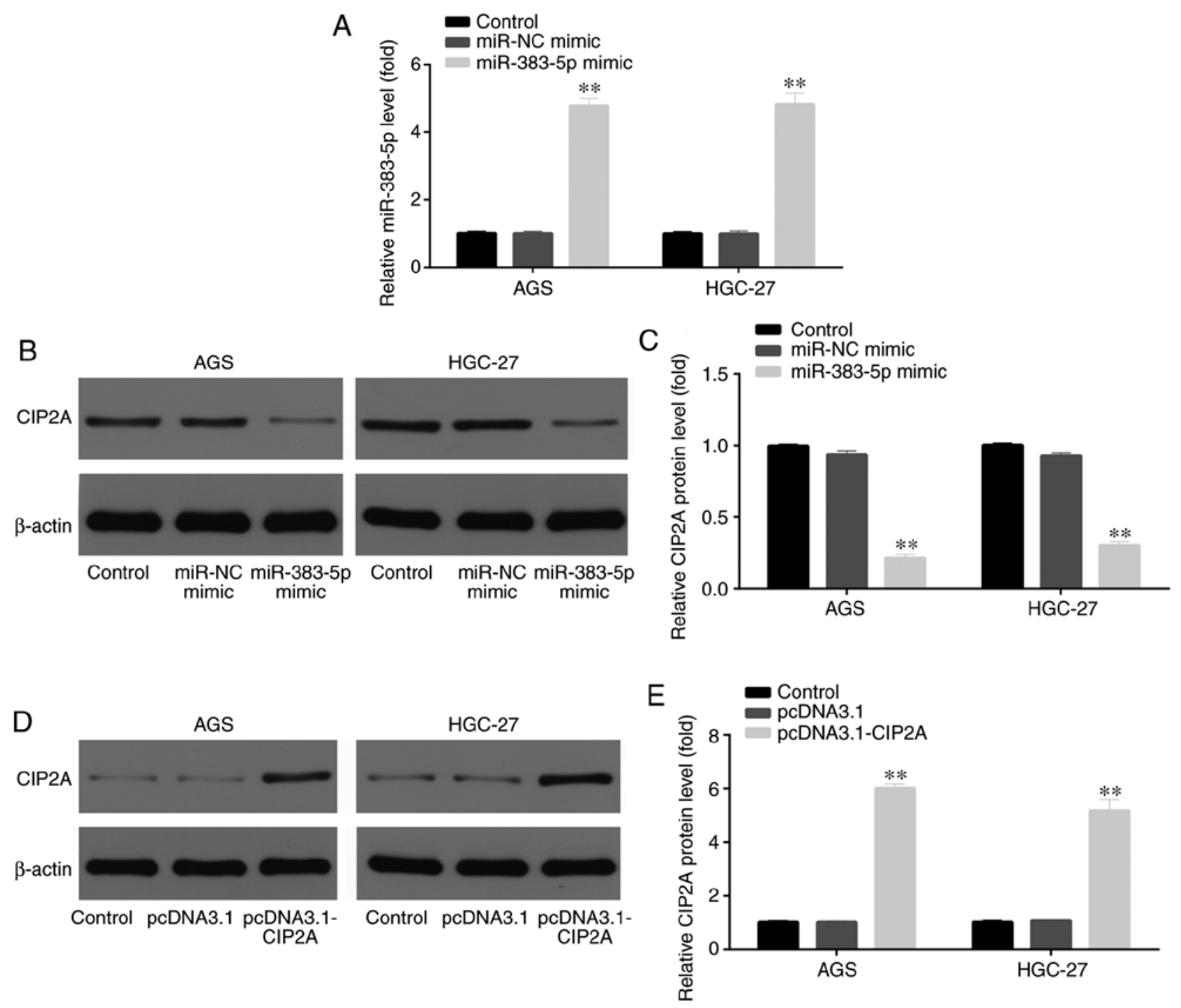

Figure 4. Transfection with miR-383-5p mimic and pcDNA3.1-CIP2A. (A) The miR-383-5p level was assessed by reverse transcription-quantitative PCR analysis. (B-E) The CIP2A protein level was assessed by western blot analysis. ${ }^{* *} \mathrm{P}<0.01 \mathrm{miR}-383-5 \mathrm{p}$ mimic vs. miR-NC mimic. CIP2A, cancerous inhibitor of PP2A.

in GC cells (23). Furthermore, compared to transfection with miR-NC mimic, transfection with miR-383-5p mimic significantly increased the protein levels of CDK4 and cyclin D1, and this effect was reversed by pcDNA3.1-CIP2A (Fig. 6E-G).
Furthermore, an increased proportion of apoptotic cells was observed in the GC cell lines, AGS and HGC-27, following transfection with miR-383-5p mimic compared to miR-NC mimic, which was reversed by transfection with pcDNA3.1-CIP2A (Fig. 7A and B). The ratio of pro-apoptotic 

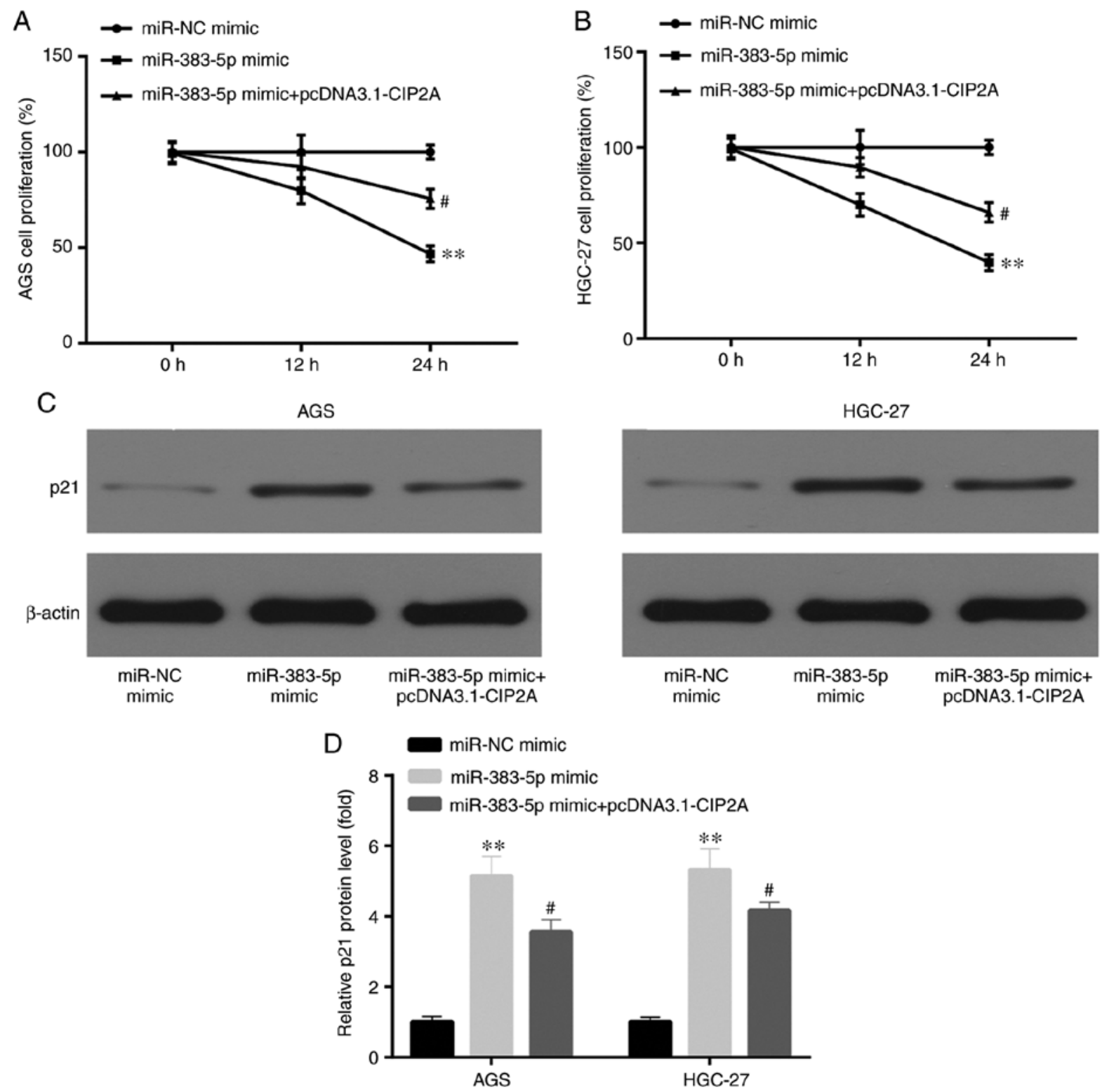

Figure 5. Effects of miR-383-5p on GC cell proliferation. (A and B) Cell proliferation was assessed by the MTT assay. (C and D) The p21 protein level was assessed by western blot analysis. ${ }^{* *} \mathrm{P}<0.01$ miR-383-5p mimic vs. miR-NC mimic. ${ }^{*} \mathrm{P}<0.05$ miR-383-5p mimic + pcDNA3.1-CIP2A vs. miR-383-5p mimic. $\mathrm{GC}$, gastric cancer; CIP2A, cancerous inhibitor of PP2A.

BAX to anti-apoptotic Bcl-2 was crucial for the promotion of cell apoptosis (24). In addition, compared to miR-NC mimic, the $\mathrm{BAX} / \mathrm{Bcl}-2$ ratio was increased by miR-383-5p mimic, which was reversed by pcDNA3.1-CIP2A (Fig. 7C and D).

\section{Discussion}

The dysregulation of miR-383 is associated with various types of cancer, such as hepatocellular carcinoma (25), pancreatic cancer (26) and glioma (27). Consistently, it was observed that miR-383-5p was also significantly decreased in GC cell lines compared with the GES-1 normal gastric epithelial cell line.

miRNAs target different mRNAs to control cancer progression $(28,29)$. For example, the overexpression of miR-383-5p inhibits ovarian cancer cell proliferation by targeting and downregulating tripartite motif-containing 27 (30);
miR-383-5p reverses hepatocellular carcinoma cell proliferation by targeting aldo-keto reductase family 1 member B10 (9). The present study demonstrated that miR-383-5p functions as a tumor suppressor by targeting and downregulating CIP2A, which was also proven by a previous study on lung cancer (23).

CIP2A overexpression has been detected in GC tumor samples (19). Consistently, the present study also demonstrated that CIP2A was significantly overexpressed in GC cell lines compared with the GES-1 normal gastric epithelial cell line.

CIP2A and miR-383-5p regulate cell proliferation. For example, CIP2A was shown to induce cell proliferation and protect cells from apoptosis in non-small-cell lung cancer $(31,32)$; furthermore, miR-383-5p reduced cell proliferation in hepatocellular carcinoma (9) and GC (14). Consistently, it was observed that miR-383-5p inhibited GC cell proliferation, and induced p21 expression which was negatively related to cell proliferation (33), by targeting 

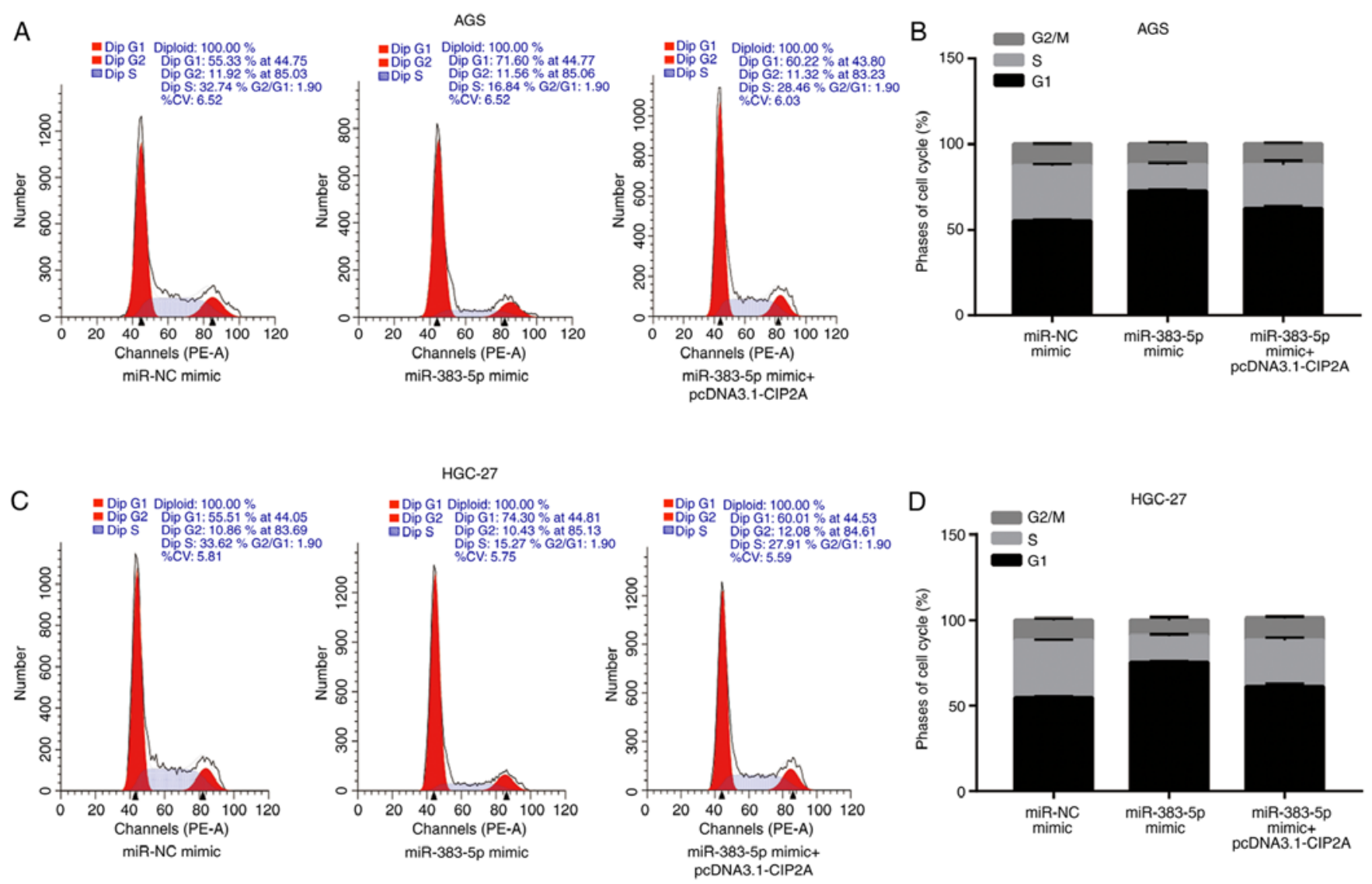

E

AGS

HGC-27
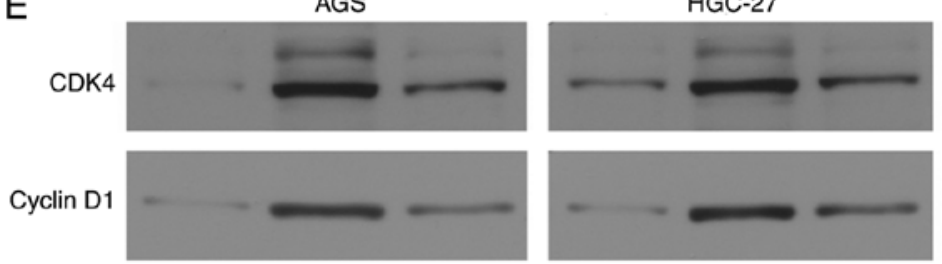

$\beta$-actin
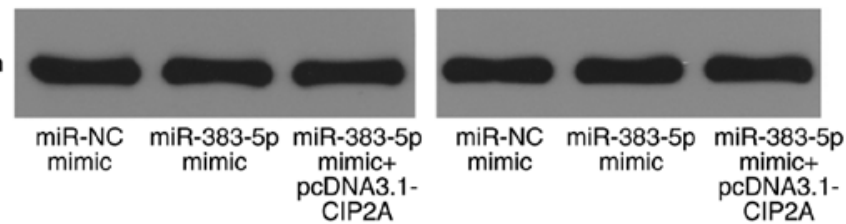

$\mathrm{F}$

miR-NC mimic miR-383-5p mimic

miR-383-5p mimic+pcDNA3.1-CIP2A

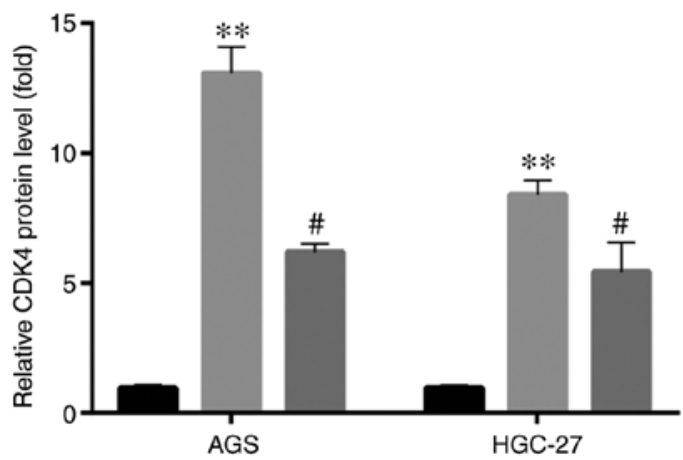

G

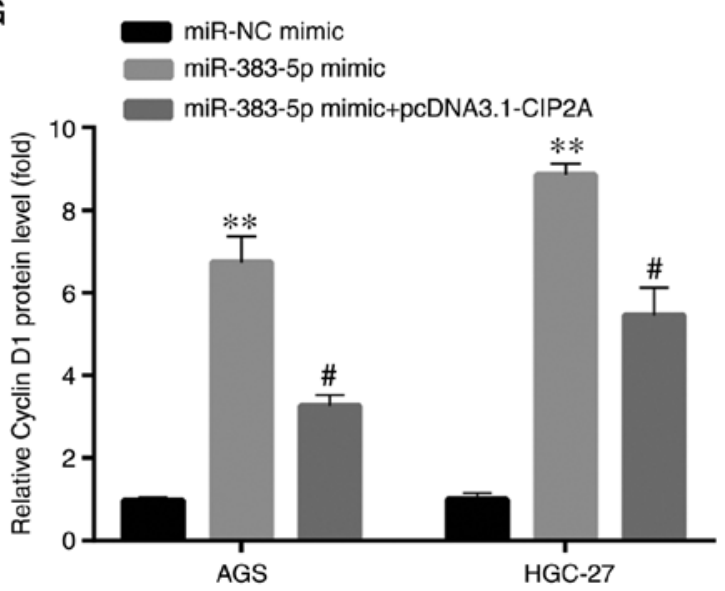

Figure 6. Effects of miR-383-5p on GC cell cycle. (A-D) Cell cycle distribution was assessed by flow cytometry. (E-G) The protein levels CDK4 and cyclin D1 were assessed by western blot analysis. ${ }^{* *} \mathrm{P}<0.01 \mathrm{miR}-383-5 \mathrm{p}$ mimic vs. miR-NC mimic. ${ }^{\prime \prime} \mathrm{P}<0.05$ miR-383-5p mimic + pcDNA3.1-CIP2A vs. miR-383-5p mimic. $\mathrm{GC}$, gastric cancer; CIP2A, cancerous inhibitor of PP2A. 

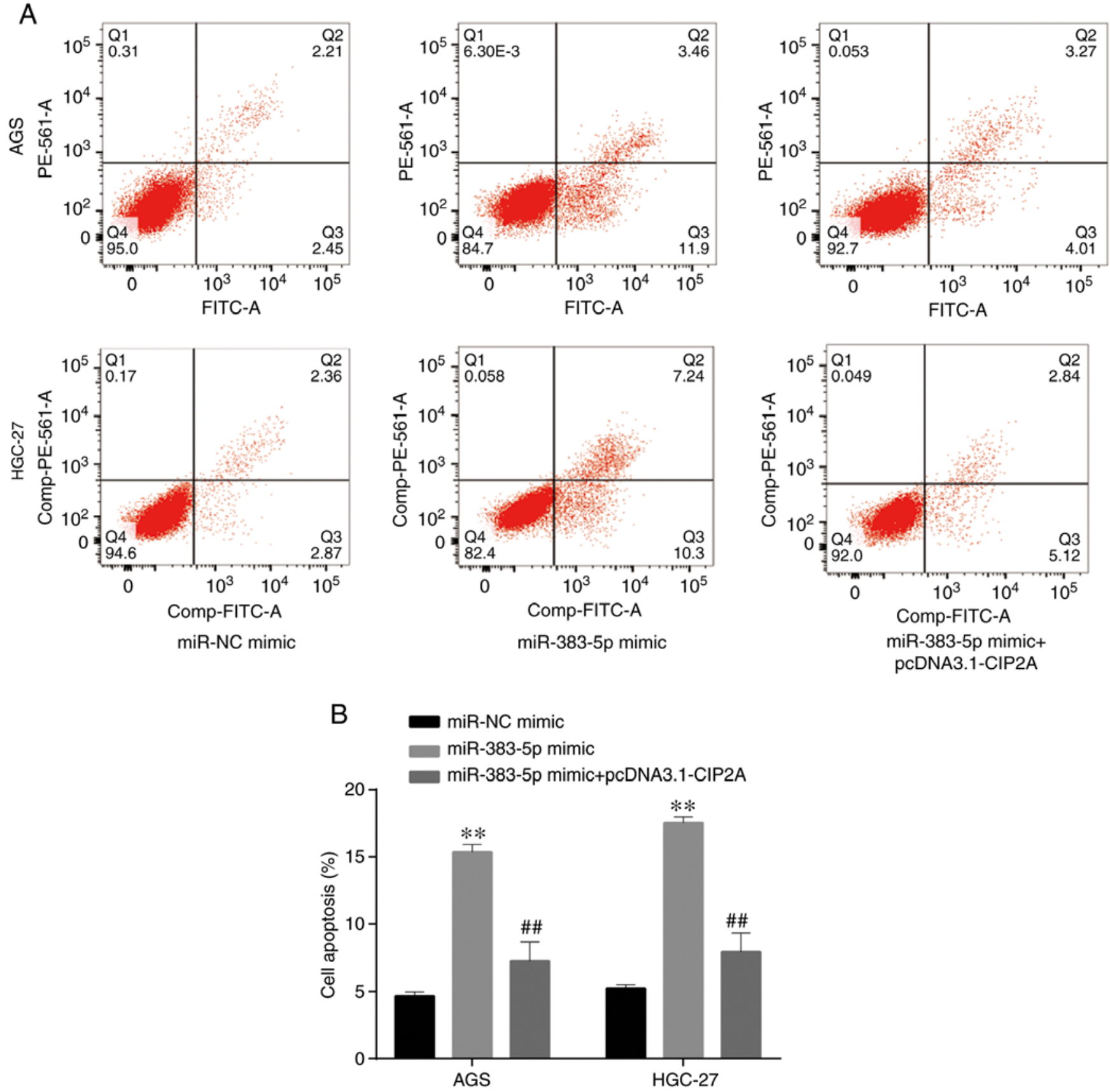

C

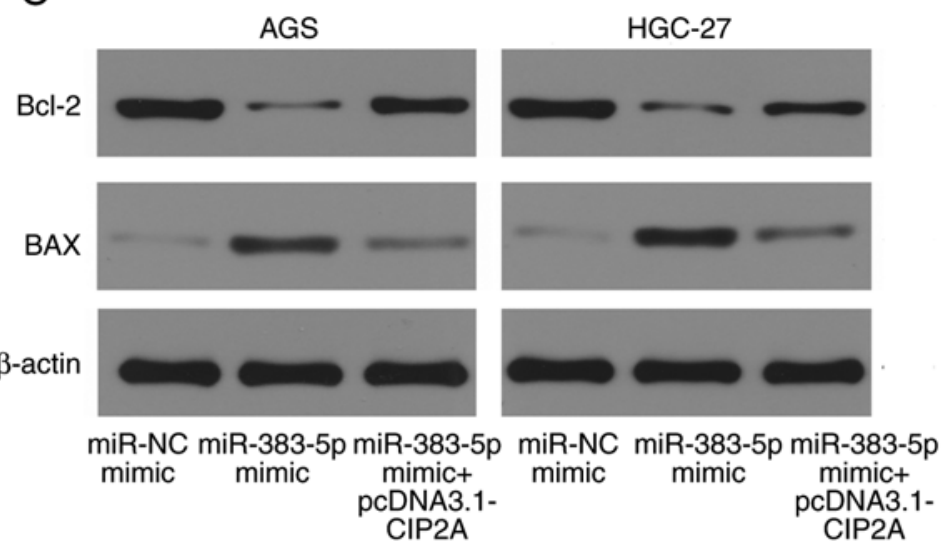

D miR-NC mimic

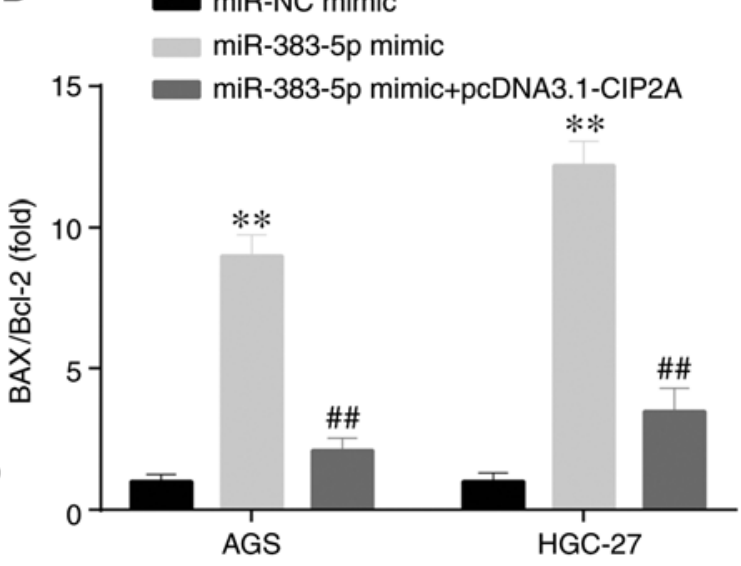

Figure 7. Effects of miR-383-5p on GC cell apoptosis. (A and B) Cell apoptosis was assessed by flow cytometry. (C and D) The protein levels of BAX and Bcl-2 were assessed by western blot analysis. ${ }^{* *} \mathrm{P}<0.01 \mathrm{miR}-383-5 \mathrm{p}$ mimic vs. miR-NC mimic. ${ }^{\# \#} \mathrm{P}<0.01$ miR-383-5p mimic + pcDNA3.1-CIP2A vs. miR-383-5p mimic. GC, gastric cancer; CIP2A, cancerous inhibitor of PP2A; Bcl-2, B-cell lymphoma 2; BAX, Bcl-2-associated X protein. 
CIP2A. In addition, miR-383-5p mimic induced $\mathrm{G}_{0} / \mathrm{G}_{1}$ arrest and CDK4/cyclin D1 expression which was positively related to the cell cycle (34), and increased cell apoptosis and the $\mathrm{BAX} / \mathrm{Bcl}-2$ ratio, which was positively associated with cell apoptosis $(35,36)$, by targeting CIP2A. Therefore, on the whole, these findings indicate that miR-383-5p inhibited the proliferation of GC cells by inducing apoptosis and cell cycle arrest in the G0/G1 phase by targeting CIP2A.

The present study clearly demonstrated that the restoration of CIP2A expression abrogated the inhibitory effects of miR-383-5p on GC cell proliferation. Taken together, the findings of the present study demonstrated that miR-383-5p exerts an inhibitory effect on GC by inhibiting CIP2A.

\section{Acknowledgements}

Not applicable.

\section{Funding}

No funding was received.

\section{Availability of data and materials}

All the datasets generated and/or analyzed during the present study are available from the corresponding author on reasonable request.

\section{Authors' contributions}

$\mathrm{XL}, \mathrm{JY}$ and QC participated in designing and conducting the experiments; XL, JY and AX analyzed the data; JC conceived the study, supervised the experiments, performed data analysis and wrote the manuscript. All the authors have read and approved the final version of the manuscript for publication.

\section{Ethics approval and consent to participate}

Not applicable.

\section{Patient consent for publication}

Not applicable.

\section{Competing interests}

The authors declare that they have no competing interests.

\section{References}

1. Torre LA, Bray F, Siegel RL, Ferlay J, Lortet-Tieulent J and Jemal A: Global cancer statistics, 2012. CA Cancer J Clin 65: 87-108, 2015

2. Yeh JM, Kuntz KM, Ezzati M, Hur C, Kong CY and Goldie SJ: Development of an empirically calibrated model of gastric cancer in two high-risk countries. Cancer Epidemiol Biomarkers Prev 17: 1179-1187, 2008.

3. Lewis BP, Burge CB and Bartel DP: Conserved seed pairing, often flanked by adenosines, indicates that thousands of human genes are microRNA targets. Cell 120: 15-20, 2005.

4. Lee Y, Ahn C, Han J, Choi H, Kim J, Yim J, Lee J, Provost P, Rådmark $\mathrm{O}, \mathrm{Kim}$ S and Kim VN: The nuclear RNase III Drosha initiates microRNA processing. Nature 425: 415-419, 2003
5. Lu J, Getz G, Miska EA, Alvarez-Saavedra E, Lamb J, Peck D, Sweet-Cordero A, Ebert BL, Mak RH, Ferrando AA, et al: MicroRNA expression profiles classify human cancers. Nature 435: 834-838, 2005.

6. Ma L, Teruya-Feldstein J and Weinberg RA: Tumour invasion and metastasis initiated by microRNA-10b in breast cancer. Nature 449: 682-688, 2007.

7. Zhao H, Guo M, Zhao G, Ma Q, Ma B, Qiu X and Fan Q: miR-183 inhibits the metastasis of osteosarcoma via downregulation of the expression of Ezrin in F5M2 cells. Int J Mol Med 30: 1013-1020, 2012.

8. Schaefer A, Jung M, Mollenkopf HJ, Wagner I, Stephan C, Jentzmik F, Miller K, Lein M, Kristiansen G and Jung K: Diagnostic and prognostic implications of microRNA profiling in prostate carcinoma. Int J Cancer 126: 1166-1176, 2010.

9. Wang J, Zhou Y, Fei X, Chen X and Chen Y: Biostatistics mining associated method identifies AKR1B10 enhancing hepatocellular carcinoma cell growth and degenerated by miR-383-5p. Sci Rep 8: 11094, 2018.

10. Zhang J, Kong X, Shi Q and Zhao B: MicroRNA-383-5p acts as a potential prognostic biomarker and an inhibitor of tumor cell proliferation, migration, and invasion in breast cancer. Cancer Biomark 27: 423-432, 2020.

11. Hu Y, Ma Y, Liu J, Cai Y, Zhang M and Fang X: LINC01128 expedites cervical cancer progression by regulating miR-383-5p/SFN axis. BMC Cancer 19: 1157, 2019.

12. Shao B, Fu X, Li X, Li Y and Gan N: RP11-284F21.9 promotes oral squamous cell carcinoma development via the miR-383-5p/MAL2 axis. J Oral Pathol Med 49: 21-29, 2020.

13. Wei C and Gao JJ: Downregulated miR-383-5p contributes to the proliferation and migration of gastric cancer cells and is associated with poor prognosis. Peer J 7: e7882, 2019.

14. Xu G, Li N,Zhang Y,Zhang J, Xu R and Wu Y: MicroRNA-383-5p inhibits the progression of gastric carcinoma via targeting HDAC9 expression. Braz J Med Biol Res 52: e8341, 2019.

15. Soo Hoo L, Zhang JY and Chan EK: Cloning and characterization of a novel $90 \mathrm{kDa}$ 'companion' auto-antigen of p62 overexpressed in cancer. Oncogene 21: 5006-5015, 2002.

16. Dong QZ, Wang Y, Dong XJ, Li ZX, Tang ZP, Cui QZ and Wang EH: CIP2A is overexpressed in non-small cell lung cancer and correlates with poor prognosis. Ann Surg Oncol 18: 857-865, 2011.

17. Huang LP, Adelson ME, Mordechai E and Trama JP: CIP2A expression is elevated in cervical cancer. Cancer Biomark 8: 309-317, 2010.

18. Vaarala MH, Väisänen MR and Ristimäki A: CIP2A expression is increased in prostate cancer. J Exp Clin Cancer Res 29: 136, 2010.

19. Li W, Ge Z, Liu C, Liu Z, Björkholm M, Jia J and Xu D: CIP2A is overexpressed in gastric cancer and its depletion leads to impaired clonogenicity, senescence, or differentiation of tumor cells. Clin Cancer Res 14: 3722-3728, 2008.

20. Zhao S, Gao X, Zang S, Li Y, Feng X and Yuan X: MicroRNA-383-5p acts as a prognostic marker and inhibitor of cell proliferation in lungadenocarcinoma by cancerous inhibitor of protein phosphatase 2A. Oncol Lett 14: 3573-3579, 2017.

21. Livak KJ and Schmittgen TD: Analysis of relative gene expression data using real-time quantitative PCR and the 2(-Delta Delta C(T)) method. Methods 25: 402-408, 2001.

22. Liu YW, Xia R, Lu K, Xie M, Yang F, Sun M, De W, Wang C and Ji G: LincRNAFEZF1-AS1 represses p21 expression to promote gastric cancer proliferation through LSD1-mediated H3K4me2 demethylation. Mol Cancer 16: 39, 2017.

23. Wang S, Wang X, Gao Y, Peng Y, Dong N, Xie Q, Zhang X, Wu Y, $\mathrm{Li}$ M and Li JL: RN181 is a tumour suppressor in gastric cancer by regulation of the ERK/MAPK-cyclin D1/CDK4 pathway. J Pathol 248: 204-216, 2019.

24. Korsmeyer SJ, Shutter JR, Veis DJ, Merry DE and Oltvai ZN: Bcl-2/Bax: A rheostat that regulates an anti-oxidant pathway and cell death. Semin Cancer Biol 4: 327-332. 1993.

25. Chen L, Guan H, Gu C, Cao Y, Shao J and Wang F: miR-383 inhibits hepatocellular carcinoma cell proliferation via targeting APRIL. Tumour Biol 37: 2497-2507, 2016.

26. Han S, Cao C, Tang T, Lu C, Xu J, Wang S, Xue L, Zhang X and $\mathrm{Li} \mathrm{M}$ : ROBO3 promotes growth and metastasis of pancreatic carcinoma. Cancer Lett 366: 61-70, 2015.

27. He Z, Cen D, Luo X, Li D, Li P, Liang L and Meng Z: Downregulation of miR-383 promotes glioma cell invasion by targeting insulin-like growth factor 1 receptor. Med Oncol 30: 557,2013 
28. Chen S, Wu J, Jiao K, Wu Q, Ma J, Chen D, Kang J, Zhao G, Shi Y, Fan D and Zhao G: MicroRNA-495-3p inhibits multidrug resistance by modulating autophagy through GRP78/mTOR axis in gastric cancer. Cell Death Dis 9: 1070, 2018.

29. Zhang F, Li K, Pan M, Li W, Wu J, Li M, Zhao L and Wang H: miR-589 promotes gastric cancer aggressiveness by a LIFR-PI3K/AKT-c-Jun regulatory feedback loop. J Exp Clin Cancer Res 37: 152, 2018

30. Jiang J, Xie C, Liu Y, Shi Q and Chen Y: Up-regulation of miR-383-5p suppresses proliferation and enhances chemosensitivity in ovarian cancer cells by targeting TRIM27. Biomed Pharmacother 109: 595-601, 2019.

31. Chao TT, Wang CY, Lai CC, Chen YL, Tsai YT, Chen PT, Lin HI, Huang YC, Shiau CW, Yu CJ and Chen KF: TD-19, an erlotinib derivative, induces epidermal growth factor receptor wild-type nonsmall-cell lung cancer apoptosis through CIP2A-mediated pathway. J Pharmacol Exp Ther 351: 352-358, 2014.

32. Lei N, Peng B and Zhang JY: CIP2A regulates cell proliferation via the AKT signaling pathway in human lung cancer. Oncol Rep 32: 1689-1694, 2014
33. Zhai H, Fesler A, Schee K, Fodstad O, Flatmark K and Ju J: Clinical significance of long intergenic noncoding RNA-p21 in colorectal cancer. Clin Colorectal Cancer 12: 261-266, 2013.

34. Pozner A, Terooatea TW and Buck-Koehntop BA: Cell-specific kaiso (ZBTB33) regulation of cell cycle through cyclin D1 and cyclin E1. J Biol Chem 291: 24538-24550, 2016.

35. Oda E, Ohki R, Murasawa H, Nemoto J, Shibue T, Yamashita T, Tokino T, Taniguchi T and Tanaka N: Noxa, a BH3-only member of the Bcl-2 family and candidate mediator of p53-induced apoptosis. Science 288: 1053-1058, 2000.

36. LeBlanc H, Lawrence D, Varfolomeev E, Totpal K, Morlan J, Schow P, Fong S, Schwall R, Sinicropi D and Ashkenazi A: Tumor-cell resistance to death receptor-induced apoptosis through mutational inactivation of the proapoptotic Bcl-2 homolog Bax. Nat Med 8: 274-281, 2002. 